\title{
Identification of Pseudomonas pseudomallei in the clinical laboratory
}

\author{
L. R. ASHDOWN
}

From the Department of Microbiology, Australian Government Health Laboratory, Townsville, Australia

SUMmary Ninety-one strains of Pseudomonas pseudomallei were tested in the API 20E system and in equivalent conventional tests. Except for utilisation of citrate there was good correlation between API and conventional tests. Seven-digit profiles were constructed from each strain after 48 hours' incubation, and numerical codes 2006 727, 2206706,2206707 , and 2206727 accounted for $77 \%$ of strains tested. API 20E, in combination with tests for heat stability of alkaline phosphatase, resistance to colistin and gentamicin, oxidative attack only of glucose, and acid from maltose, was found to provide a simple method for positive identification of all strains of this organism in two days.

Melioidosis is a rare, infectious disease with primary endemic foci in South-east Asia, northern Australia, and Central America. In the acute form, it is often fulminating and fatal, while chronic forms of the disease have been reported in veterans of south-east Asian conflicts and in visitors and residents of endemic areas (Howe et al., 1971). Clinical diagnosis is made by isolation of the causative bacterium, Pseudomonas pseudomallei, supported by the demonstration of high specific antibody. Identification of an isolate as Ps. pseudomallei is, however, difficult due to sharing of physical and biochemical properties with other bacteria and because of the infrequency with which it is encountered, while diagnosis is often delayed since the isolate is frequently submitted to a reference laboratory for identification (Zierdt and Marsh, 1971). Final confirmation is made by serology using specific antiserum against $P$ s. pseudomallei, but this is rarely a routine procedure in clinical laboratories as specific antigen and reference antisera for this uncommon disease are not easily obtained. A simple method for positive identification of Ps. pseudomallei that is within the scope of the small diagnostic laboratory seems to be an obvious requirement.

The commercially produced kit system, API 20E (Analytab Products Inc, New York, USA), is currently used in many laboratories for the identification of Enterobacteriaceae and other Gramnegative bacteria. The kit consists of 20 plastic cupules containing dehydrated media which are

Received for publication 16 November 1978 inoculated with a suspension of the test organism and incubated at $37^{\circ} \mathrm{C}$ from $18-24$ hours to $36-48$ hours, depending on the number of positive reactions. Twenty-one tests in this system are divided into seven groups of three, and each test is assigned a number. By this method a seven-digit profile of reactions of the test organism is determined, and the profile number is matched against numbers in a computerised Analytical Profile Index to identify the organism. However, strains of Ps. pseudomallei are not included in the range of organisms in the API data base, and no profile numbers for $P s$. pseudomallei exist in the Index at this time (August, 1978).

Liu (1966) reported that alkaline phosphatases of $P$ s. pseudomallei and $P$ s. aeruginosa were heat resistant while those of other pseudomonads were heat labile. This test together with susceptibility to colistin and gentamicin, oxidation-fermentation reactions of glucose, and acid reaction from maltose were considered as valuable tests in the differentiation of Ps. pseudomallei from other Gram-negative bacteria. The purpose of this paper is to compare tests of the API system against conventional methods, construct seven-digit profiles for Ps. pseudomallei, and evaluate API $20 \mathrm{E}$ with the above additional tests as criteria for identification of Ps. pseudomallei from other oxidase-positive Gram-negative bacilli.

\section{Material and methods}

TEST ORGANISMS

Ninety-one strains of Ps. pseudomallei were available 
for testing: 37 strains were donated from the School of Public Health and Tropical Medicine, University of Sydney, 23 strains from the Animal Health Station, Townsville, 5 strains from the Australian Government Health Laboratory (AGHL), Rockhampton, and 26 strains from the AGHL, Townsville. Other organisms tested were: 18 strains of $P s$. aeruginosa, 10 strains of $P$ s. cepacia, 9 strains of Ps. stutzeri, 8 strains of Ps. fluorescens, 3 strains of Alcaligenes bronchisepticus, 2 strains of $A$. faecalis, and 2 strains of Flavobacterium species. These strains were isolated by me at the AGHL, Townsville, and each organism was identified according to Cowan (1974).

\section{CULTURE STUDIES}

The API 20E kit tests were performed according to the manufacturer's instructions which include details on inoculation and test interpretation. API kits were inoculated with test strains of pseudomonads suspended in sterile normal saline and incubated for two days at $37^{\circ} \mathrm{C}$, and reactions were noted after 24 and 48 hours. Reagents were added to the system after 48 hours' incubation. Seven-digit profiles from API reactions of each strain were formulated according to the manufacturer's instructions. A sample of profile construction is given in Table 1 for strain NCTC 8016.

Conventional tests were carried out with test strains of Ps. pseudomallei using the media and methods of Cowan (1974). Specific methods used

Table 1 Construction of seven-digit profile for Pseudomonas pseudomallei, strain NCTC 8016

\begin{tabular}{|c|c|c|c|c|}
\hline $\begin{array}{l}\text { Value of } \\
\text { test }\end{array}$ & Test & $\begin{array}{l}\text { Positive } \\
\text { reaction }\end{array}$ & $\begin{array}{l}\text { Value } \\
\text { assigned }\end{array}$ & $\begin{array}{l}\text { Numericol* } \\
\text { code }\end{array}$ \\
\hline 1 & ONPG & - & 0 & \\
\hline 2 & Arginine dihydrolase & + & 2 & 2 \\
\hline 4 & Lysine decarboxylase & - & 0 & \\
\hline 1 & $\begin{array}{l}\text { Ornithine decarboxy- } \\
\text { lase }\end{array}$ & - & 0 & \\
\hline 2 & Citrate utilisation & + & 2 & 2 \\
\hline 4 & $\mathrm{H}_{2} \mathrm{~S}$ production & - & $\mathbf{0}$ & \\
\hline 1 & Urease production & - & 0 & \\
\hline 2 & $\begin{array}{l}\text { Tryptophan deamina- } \\
\text { tion }\end{array}$ & - & 0 & 0 \\
\hline 4 & Indole production & - & $\mathbf{0}$ & \\
\hline 1 & Acetoin production & - & 0 & \\
\hline 2 & Gelatin liquefaction & + & 2 & 6 \\
\hline 4 & Acid from glucose & + & 4 & \\
\hline 1 & Acid from mannitol & + & 1 & \\
\hline 2 & Acid from inositol & + & 2 & 7 \\
\hline 4 & Acid from sorbitol & + & 4 & \\
\hline 1 & Acid from rhamnose & - & 0 & \\
\hline 2 & Acid from sucrose & - & 0 & 0 \\
\hline 4 & Acid from melibiose & - & 0 & \\
\hline 1 & Acid from amygdalin & + & 1 & \\
\hline 2 & Acid from arabinose & + & 2 & 7 \\
\hline 4 & $\begin{array}{l}\text { Cytochrome oxidase } \\
\text { activity }\end{array}$ & + & 4 & \\
\hline
\end{tabular}

*Profile is given by 2206707 and only one profile exists for this strain were: $\beta$ galactosidase production (ONPG test), decarboxylase reactions (method 2), citrate utilisation (method 2), $\mathrm{H}_{2} \mathrm{~S}$ production (method 1), urease production (method 2), phenylpyruvic acid production (method 2), indole production (method 2), acetoin production (V-P test, method 1), gelatin liquefaction (method 5), acid from carbohydrates (open tubes of OF basal medium with final concentration of all carbohydrates $1 \mathrm{~g} / 100 \mathrm{ml}$ ), cytochrome oxidase activity (method 1). Tests for acid production from amygdalin were not performed.

Heat stability of alkaline phosphatase, resistance to colistin and gentamicin, oxidation-fermentation reactions from glucose and acid reaction from maltose were performed on all test strains. Heat resistance of alkaline phosphatase was determined as described by Liu (1966). A heavy 1-ml suspension of each test organism from an overnight growth on agar medium containing $0.2 \%$ peptone and $0.05 \%$ yeast extract was made in $0.02 \mathrm{M}$ Tris buffer $(\mathrm{pH} 8.0)$. The inoculum was divided into two tubes, and one tube was heated at $70^{\circ} \mathrm{C}$ for 20 minutes. Equal volumes of $0.1 \% p$-nitrophenylphosphate were added to both heated and unheated tubes and incubated overnight at $37^{\circ} \mathrm{C}$ and colour reactions were noted. Alkaline phosphatase was considered to be heat resistant if a yellow colour was produced in both tubes, and heat labile if colour was formed only in the unheated tube.

Susceptibility to colistin and gentamicin was determined by the method of Bauer et al. (1966). Test strains were considered resistant if zone diameters were $8 \mathrm{~mm}$ or less for colistin and $12 \mathrm{~mm}$ or less for gentamicin. Oxidation-fermentation reactions from glucose were carried out as described by Hugh and Leifson (1953), while acid reaction from maltose was determined using the OF basal medium of Hugh and Leifson (1953) with $1 \mathrm{~g}$ of maltose $/ 100 \mathrm{ml}$ of medium in unsealed tubes.

\section{Results}

Individual tests of the API system correlated well with conventional methods, except for the test for utilisation of citrate (Table 2), with which 32 strains of $\boldsymbol{P}$ s. pseudomallei gave false negative reactions and one strain gavea false positive reaction. After 24 hours' incubation, arginine dihydrolase, glucose, mannitol, inositol, sorbitol, and arabinose generally gave weak reactions in both systems, becoming strongly positive after 48 hours' incubation. Four strains failed to give an acid reaction with glucose in the API system but were positive after 48 hours' incubation in conventional media. Gelatin liquefaction occurred with all strains after 24 hours' incubation. Seven-digit profiles were constructed from each 
Table 2 Comparison of tests of API system with conventional tests using 91 strains of Pseudomonas pseudomallei

\begin{tabular}{lrcr}
\hline Test & $\begin{array}{c}\text { API } \\
\text { system }\end{array}$ & $\begin{array}{c}\text { Conventional } \\
\text { tests }\end{array}$ & $\begin{array}{c}\text { No. of strains } \\
\text { in disagreement } \\
\text { with conventional } \\
\text { tests }\end{array}$ \\
\hline ONPG & & & 0 \\
Arginine dihydrolase & 0 & 0 & 2 \\
Lysine decarboxylase & 98 & 100 & 0 \\
Ornithine decarboxylase & 0 & 0 & 0 \\
Citrate utilisation & 0 & 0 & 33 \\
HsS production & 63 & 98 & 0 \\
Urease production & 0 & 0 & 0 \\
Tryptophan deamination & 0 & 0 & 0 \\
Indole production & 0 & 0 & 0 \\
Acetoin production & 0 & 0 & 0 \\
Gelatin liquefaction & 0 & 0 & 0 \\
Acid from glucose & 100 & 100 & 4 \\
Acid from mannitol & 95 & 100 & 0 \\
Acid from inositol & 100 & 100 & 0 \\
Acid from sorbitol & 100 & $98(2)$ & 0 \\
Acid from rhamnose & 100 & $99(1)$ & 2 \\
Acid from sucrose & 0 & $0(2)$ & 0 \\
Acid from melibiose & 43 & $40(3)$ & 4 \\
Acid from amygdalin & 0 & $2(3)$ & -6 \\
Acid from arabinose & 60 & NT & 0 \\
Cytochrome oxidase activity & 100 & 100 & 0 \\
\hline & 93 & $96(4)$ & 6 \\
\hline & & & 0 \\
\hline
\end{tabular}

*Figures indicate percent positive at $\mathbf{4 8}$ hours; those in parentheses indicate percent positive after $\mathbf{4 8}$ hours

NT $=$ not tested

pseudomonad strain, and the numerical codes are given in Table 3.

All strains of Ps. pseudomallei and Ps. aeruginosa produced alkaline phosphatases which were heat stable, while those from other bacteria tested were heat labile. One strain of $A$. bronchisepticus and two strains of Flavobacterium species showed no evidence of alkaline phosphatase production. All strains of Ps. pseudomallei were resistant to colistin and gentamicin, oxidatively attacked glucose, and gave acid reactions from maltose. Results of tests from all strains are summarised in Table 4.

\section{Discussion}

Except for the test for utilisation of citrate, there was no significant difference between results from conventional tests and those obtained with API 20E. Butler et al. (1975) and Holmes et al. (1977) also found disagreement with API citrate and the conventional test. Although in some cases reactions could be read after 24 hours' incubation, it was found necessary to reincubate the API strips for a further 24 hours to obtain satisfactory readings. Reactions with API 20E were relatively consistent, with profiles 2006 727, 2206 706, 2206 707, and 2206727 accounting for $77 \%$ of all strains tested. Results of biochemical tests of strains of Ps. pseudomalle $i$ were in agreement with those of other workers
Table 3 Comparison of seven-digit profiles from pseudomonads tested with API 20 E after 48 hours' incubation

\begin{tabular}{|c|c|c|}
\hline Organism & Profile & No. of patterns \\
\hline $\begin{array}{l}\text { Ps. pseudomallei } \\
\text { (91 strains) }\end{array}$ & $\begin{array}{l}0006727 \\
0206706 \\
2006704 \\
2006706 \\
2006707 \\
2006726 \\
2006727 \\
2202704 \\
2202706 \\
2206704 \\
2206706 \\
2206707 \\
2206727\end{array}$ & $\begin{array}{r}1 \\
1 \\
1 \\
4 \\
5 \\
1 \\
22 \\
1 \\
3 \\
4 \\
21 \\
12 \\
15\end{array}$ \\
\hline $\begin{array}{l}\text { Ps. aeruginosa } \\
\text { (18 strains) }\end{array}$ & $\begin{array}{l}0206006 \\
2002004 \\
2006004 \\
2206004 \\
2206006\end{array}$ & $\begin{array}{l}1 \\
1 \\
5 \\
9 \\
1\end{array}$ \\
\hline $\begin{array}{l}\text { Ps. cepacia } \\
\text { (10 strains) }\end{array}$ & $\begin{array}{l}0004004 \\
0206006 \\
1204004 \\
4304004 \\
5304004\end{array}$ & $\begin{array}{l}3 \\
1 \\
1 \\
4 \\
1\end{array}$ \\
\hline $\begin{array}{l}\text { Ps. stutzeri } \\
\text { (9 strains) }\end{array}$ & $\begin{array}{l}0000004 \\
0004004 \\
0004104\end{array}$ & $\begin{array}{l}1 \\
5 \\
3\end{array}$ \\
\hline $\begin{array}{l}\text { Ps. fluorescens } \\
\text { (8 strains) }\end{array}$ & $\begin{array}{l}0204004 \\
2000004 \\
2200004\end{array}$ & $\begin{array}{l}2 \\
5 \\
1\end{array}$ \\
\hline
\end{tabular}

except for urease production which Cowan (1974) classed as a variable reaction. Hugh and Gilardi (1974) reported $35 \%$ of 26 strains tested as urease positive but in this series all 91 strains of Ps. pseudomallei tested in both API and conventional medium were negative for urease production.

Heat resistance of alkaline phosphatase proved to be a valuable test for the differentiation of $P \boldsymbol{s}$. aeruginosa and Ps. pseudomallei from other pseudomonads, especially $P$ s. stutzeri and Ps. cepacia. These resemble Ps. pseudomallei biochemically and morphologically, producing dry and wrinkled colonies which are similar to the rugose form of Ps. pseudomallei. However, as Liu (1966) pointed out, alkaline phosphatases of many enteric bacilli are heat resistant, and this test is valuable only for differentiation of species within the genus Pseudomonas. Generally, Ps. aeruginosa is readily differentiated from Ps. pseudomallei; however, some nonpyocyanogenic strains which are resistant to gentamicin and colistin can pose a problem in identification, and effectively mimic Ps. pseudomallei (Zierdt and Marsh, 1971). Ps. aeruginosa can be eliminated by its failure to react with maltose to produce an acid reaction. The oxidation-fermentation reaction separates glucose oxidising bacteria from other fermenta- $\AA$ tive and non-fermentative organisms. Hall and $\underset{2}{2}$ Manion (1973) found that approximately one-third 
Table 4 Comparative value of tests for differentiation of Pseudomonas pseudomallei from other commonly isolated Gram-negative bacteria

\begin{tabular}{|c|c|c|c|c|c|c|c|}
\hline \multirow[t]{3}{*}{ Organism } & \multirow{3}{*}{$\begin{array}{l}\text { No. of strains } \\
\text { tested }\end{array}$} & \multicolumn{6}{|l|}{ Tests } \\
\hline & & \multirow{2}{*}{$\begin{array}{l}\text { Heat stable* } \\
\text { alkaline } \\
\text { phosphatose }\end{array}$} & \multicolumn{2}{|c|}{ Resistance* to: } & \multirow{2}{*}{$\begin{array}{l}\text { Oxidation } \dagger \\
\text { of } \\
\text { glucose }\end{array}$} & \multirow{2}{*}{$\begin{array}{l}\text { Fermentation } \dagger \\
\text { of } \\
\text { glucose }\end{array}$} & \multirow{2}{*}{$\begin{array}{l}\text { Acid } \dagger \\
\text { from } \\
\text { maltose }\end{array}$} \\
\hline & & & Colistin & Gentamicin & & & \\
\hline Ps.pseudomallei & 91 & 100 & 100 & 100 & 100 & $\mathbf{0}$ & 100 \\
\hline Ps. aeruginosa & 18 & 100 & 0 & 16 & 100 & 0 & 0 \\
\hline Ps. cepacia & 10 & 0 & 80 & 90 & 100 & 0 & 100 \\
\hline Ps. stutzeri & 9 & 0 & 0 & 0 & 100 & 0 & 100 \\
\hline Ps. fluorescens & 8 & 0 & 0 & 0 & 100 & 0 & 75 \\
\hline A. bronchisepticus & 3 & $0+$ & 0 & 0 & 0 & 0 & $\mathbf{0}$ \\
\hline A. faecalis & 2 & 0 & 0 & 0 & 0 & $\mathbf{0}$ & $\mathbf{0}$ \\
\hline Flavobacterium sp & 2 & NR & 0 & 0 & 0 & 0 & 0 \\
\hline
\end{tabular}

* Percentage positive after overnight incubation

tPercentage positive after 48 hours' incubation

$\ddagger$ No reaction occurred with one strain

NR = no reaction

of 51 strains of $P s$. pseudomallei were sensitive to $4 \mathrm{mg} / \mathrm{l}$ of gentamicin, while other workers (Eickhoff et al., 1970; Franklin, 1971) have reported the organism to be resistant to gentamicin. All 91 strains of Ps. pseudomallei tested in this series were resistant to gentamicin by the disk-diffusion technique, and on subsequent testing they were found to be resistant to levels greater than $8 \mathrm{mg} / \mathrm{l}$ of gentamicin by the agar-dilution method (Ashdown, 1979).

API 20E was originally designed for the identification of fermentative organisms of the Enterobacteriaceae, and in recent years the manufacturer has indicated that the system is suitable for the differentiation of non-fermentative Gram-negative bacilli. Morris et al. (1978) have described the problems associated with API 20E for the identification of saccharolytic pseudomonads but they found that the system can be adequately used to separate Pseudomonas as a genus from other genera. The advantages of the multitest strip such as space saving, speed in inoculation and reading of reactions, accuracy, simplicity, computerised index, and low cost over conventional tests tend to promote the use of the system in the clinical laboratory. In this study it was found that because of the distinctive profile numbers for $P$ s. pseudomallei and good correlation with conventional tests, API 20E can satisfactorily be used routinely in the diagnostic laboratory as a basis for screening and presumptive identification of Ps. pseudomallei.

By complementing API with tests for heat stability of alkaline phosphatase, resistance to colistin and gentamicin, oxidative attack only of glucose and acid from maltose, a simple feasible system for positive identification of $P$ s. pseudomallei without the need of specific antiserum is available to the small clinical laboratory.

\section{References}

Ashdown, L. R. (1979). An improved screening technique for isolation of Pseudomonas pseudomallei from clinical specimens. Pathology (In press).

Bauer, A. W., Kirby, W. M. M., Sherris, J. C., and Turck, M. (1966). Antibiotic susceptibility testing by a standardized single disk method. American Journal of Clinical Pathology, 45, 493-496.

Butler, D. A., Lobregat, C. M., and Gavan, T. L. (1975). Reproducibility of the Analytab (API 20E) system. Journal of Clinical Microbiology, 2, 322-326.

Cowan, S. T. (1974). Cowan and Steel's Manual for the Identification of Medical Bacteria, 2nd edition. Cambridge University Press, London.

Eickhoff, T. C., Bennett, J. V., Hayes, P. S., and Feeley, J. (1970). Pseudomonas pseudomallei: susceptibility to chemotherapeutic agents. Journal of Infectious Diseases, 121, 95-102.

Franklin, M. (1971). Effect of gentamicin on Pseudomonas pseudomallei. Journal of Infectious Diseases, 124S, S30-S32.

Hall, W. H., and Manion, R. E. (1973). Antibiotic susceptibility of Pseudomonas pseudomallei. Antimicrobial Agents and Chemotherapy, 4, 193-195.

Holmes, B., Willcox, W. R., Lapage, S. P., and Malnick, H. (1977). Test reproducibility of the API (20E), Enterotube, and Pathotec systems. Journal of Clinical Pathology, 30, 381-387.

Howe, C., Sampath, A., and Spotnitz, M. (1971). The pseudomallei group: A review. Journal of Infectious Diseases, 124, 598-606.

Hugh, R., and Gilardi, G. L. (1974). Pseudomonas. In Manual of Clinical Microbiology, edited by E. H. Lennette, E. H. Spaulding, and J. P. Truant, pp. 250-269. American Society for Microbiology, Washington, DC.

Hugh, R., and Leifson, E. (1953). The taxonomic significance of fermentative versus oxidative metabolism of carbohydrates by various Gram negative bacteria. Journal of Bacteriology, 66, 24-26.

Liu, P. V. (1966). Differentiation of pathogenic pseudomonads by heat resistance of alkaline phosphatase. 
American Journal of Clinical Pathology, 45, 639-642.

Morris, M. J., Young, V. M., and Moody, M. R. (1978). Evaluation of a multitest system for identification of saccharolytic pseudomonads. American Journal of Clinical Pathology, 69, 41-47.

Zierdt, C. H., and Marsh, H. H., III (1971). Identifi- cation of Pseudomonas pseudomallei. American Journal of Clinical Pathology, 55, 596-603.

Requests for reprints to: Dr L. R. Ashdown, Microbiology Department, Australian Department of Health, Pathology Laboratory, MSO Box 5278, Townsville, Qld. 4810, Australia. ld. 